\title{
RÁDIO USP, \\ A FM QUE TOCA \\ TODAS AS LÍNGUAS
}

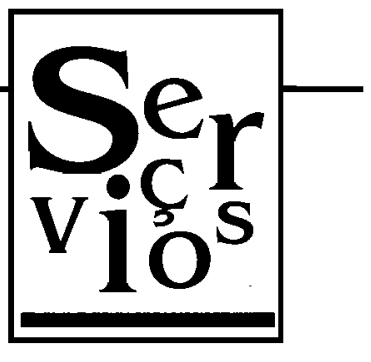

Criada em 11 de outubro de 1977, a Rádio USP FM tinha como objetivos preencher a lacuna de emissoras educativas na Grande São Paulo e, ao mesmo tempo, proporcionar um canal de comunicação entre a Universidade de São Paulo e a sociedade. Ao longo de seus 18 anos de existência vem desenvolvendo essas metas e recebeu diversos prêmios de associações como Associação Paulista de Críticos de Artes - APCA e Câmara Brasileira do Livro por sua linha de trabalho diferenciada.

A emissora, operando em $93,7 \mathrm{Mhz}$, mantém uma programação voltada à divulgação das atividades da Universidade de São Paulo por meio de boletins informativos, clips educativos e entrevistas com seus docentes e pesquisadores em programas levados ao ar diariamente. A emissora mantém espaço permanentemente aberto para debates sobre temas de interesse da sociedade, sempre com a óptica da USP. A prestação de serviços recebe destaque em programas especiais voltados aos vestibulandos em parceria com o Cursinho da Poli e pelo apoio, através de divulgação, a eventos culturais realizados na cidade de São Paulo, tais como espetáculos teatrais, musicais, exposições e campanhas educativas. A Rádio tem ainda a preocupação de adequar toda sua programação, educativa ou não, a uma linguagem ágil e acessível, fazendo com que todos esses temas, de real impor- tância para a sociedade, possam ser compreendidos com facilidade.

A programação musical vem se caracterizando como uma opção à extrema segmentação das atuais emissoras de FM, oferecendo ao público o melhor de todos os ritmos musicais, da MPB ao Rock, do Jazz ao Samba, passando por ritmos regionais e de outras culturas.

A emissora busca difundir gêneros musicais que não encontram espaço na maioria das emissoras comerciais como a música étnica e a erudita, as quais, em horários especiais, são apresentadas ao público acompanhadas de informações e explicações, sempre com o objetivo de formar novos ouvintes para os gêneros.

A Rádio USP também vem investindo em convênios com emissoras internacionais, com a finalidade de enriquecer sua programação. É o caso, por exemplo, da BBC de Londres, da qual recebemos boletins informativos, programas especiais e

\section{A AUTORA}

\section{Lígia Trigo}

Jomalista, diretora do Departamento de Radiodifusão (Rádio USP) da Coordenadoria de Comunicação Social da USP desde janeiro de 1994. 
documentários que são retransmitidos periodicamente. Já com A Voz da América, a Rádio USP, além de retransmitir seus noticiários, funciona como geradora de informações. Semanalmente, informações sobre a USP (suas pesquisas, seminários, programas) são veiculadas para 40 rádios brasileiras em todo o país pelo satélite da emissora norte-americana.

O público da emissora é formado em sua maioria por homens, nível sócio-econômico A/B, com mais de 25 anos, nível superior completo, economicamente ativos.

A Rádio USP fala hoje para um público predominantemente composto por formadores de opinião e atinge, em média, quatro mil e duzentos ouvintes por minuto, chegando, em seu horário principal (das 6 às 19h), a sete mil ouvintes por minuto.

Atualmente, todos os esforços da rádio estão voltados para a solução de seus problemas de recepção na cidade. Para isso, um novo transmissor foi adquirido, passando a funcionar a partir de junho/96, aumentando a potência irradiada pela emissora e melhorando a recepção de seu sinal em vários pontos de São Paulo. Também está sendo desenvolvido um projeto de adequação de sua antena, que contribuirá efetivamente para resultados melhores de recepção.

Por tudo isso optou-se pelo slogan "A FM que toca todas as línguas", uma referência não só às várias linguagens musicais mas também à diversidade de idéias e opiniões apresentadas em seus vários programas e à variedade de opções em termos de programação oferecidas ao público ouvinte. Com isso, acreditamos que a Rádio USP está cumprindo sua finalidade de emissora educativa e os princípios de sua criação.

\section{PROGRAMAÇÃO}

REPÓRTER USP - Noticiário de uma hora de duração com as principais notícias do país (Política, Economia, Cultura, Esportes), a repercussão desses fatos junto a especialistas da Universidade e notícias internacionais em boletins da Voz da América e BBC. Apresenta ainda matérias sobre projetos, pesquisas e atividades desenvolvidas na Universidade. Divulga fatos de interesse para a Comunidade Acadêmica e agenda de cursos, seminários, simpósios. De segunda a sexta-feira, das 7 às $8 \mathrm{~h}$.

\section{BOLETINS INFORMATIVOS -} Durante a semana, são cinco informativos (com notícias gerais) e três sobre as atividades da USP, com cerca de cinco minutos de duração cada. Trazem também entrevistas com professores e pesquisadores da Universidade. No fim de semana, são seis edições com notícias e matérias sobre a USP e atividades de cultura e lazer. De segunda a sexta-feira, às $9 \mathrm{~h}, 10 \mathrm{~h}, 11 \mathrm{~h}, 14 \mathrm{~h}$, $16 \mathrm{~h}, 17 \mathrm{~h}$ e $17 \mathrm{~h} 55$. Sábados e Domingos, às $8 \mathrm{~h}, 9 \mathrm{~h}, 10 \mathrm{~h}, 13 \mathrm{~h}, 14 \mathrm{~h}$ e $17 \mathrm{~h}$.

CLIPS - Entrevistas gravadas com docentes da Universidade dando informações sobre saúde, meio ambiente, economia, mulher etc. Três têm temas fixos: Clip Cultura (voltado principalmente aos lançamentos do mercado editorial), Clip tecnologia (produzido pelo CECAE - Coordenadoria Executiva de Cooperação Universitária e de Atividades Especiais, enfocando atendimentos realizados pelo DisqueTecnologia) e Clip informática (com as novidades tecnológicas que estão sendo lançadas). Os outros quatro têm sua temática renovada trimestralmente. Têm cerca de três minutos de duração. De segunda a sex- 
ta, em edições às $6 \mathrm{~h} 30,8 \mathrm{~h} 30,9 \mathrm{~h} 30,1 \mathrm{~h} 30$, $13 \mathrm{~h} 30,14 \mathrm{~h} 30,15 \mathrm{~h} 30,16 \mathrm{~h} 30,17 \mathrm{~h} 30,20 \mathrm{~h}$ e $20 \mathrm{~h} 55$.

ENFOQUE - Programa de entrevista tendo como foco a cultura. Todo programa traz três entrevistados, sendo que um é necessariamente do meio musical. Traz ainda dicas de atividades culturais, lançamentos de discos, livros e vídeos. De segunda a sexta-feira, das $12 \mathrm{~h}$ às $13 \mathrm{~h}$.

SÓ BRASIL - O melhor da música popular brasileira de todos os tempos. De segunda a sexta, das $6 \mathrm{~h}$ às $7 \mathrm{~h}$.

SOM DA USP - Programação musical destacando o melhor da música popular brasileira e internacional. Ênfase para as diferentes linguagens musicais. De segunda a sexta, das $8 \mathrm{~h}$ às $12 \mathrm{~h}$ e das $13 \mathrm{~h}$ às $18 \mathrm{~h}$. Sábados, das $8 \mathrm{~h}$ às $11 \mathrm{~h}$, das $12 \mathrm{~h}$ às $15 \mathrm{~h} \mathrm{e}$ das $15 \mathrm{~h} 30$ às $18 \mathrm{~h}$. Domingos, das $7 \mathrm{~h}$ às $11 \mathrm{~h}$, das $12 \mathrm{~h}$ às $15 \mathrm{~h}$ e das $16 \mathrm{~h}$ às $18 \mathrm{~h}$.

TOQUE OUTRA VEZ - Programa musical que apresenta seleções elaboradas por ouvintes da emissora e apresentadas por cartas ou fax. As melhores programações são selecionadas e apresentadas no mês seguinte. Diariamente, das $18 \mathrm{~h}$ às $19 \mathrm{~h}$.

TEMPO DE $\boldsymbol{J A Z Z}$ - Série mostrando as mais variadas tendências do Jazz. Cada programa é produzido e apresentado por um programador diferente. De segunda a sexta, das $21 \mathrm{~h}$ às $22 \mathrm{~h}$.

Segunda - Soul Jazz

Terça - What's New: somente com lançamentos inéditos no país. Produção e apresentação de Carlos Calado, Ayrton Martini e Flávio Mancini.
Quarta-Blues: o melhor do blues de todos os tempos e os destaques nacionais no gênero. Produção e apresentação de Caio Ávila.

Quinta - Jazz Party: os diferentes idiomas do jazz. Produção e apresentação de João Bandeira.

Sexta - Swingtime: a produção das bigbands. Produção e apresentação de Reynaldo Mendes de Souza.

TEMPO DE CONCERTO - Série enfocando a música erudita. Cinco programas semanais produzidos e apresentados por professores do Departamento de Música da Escola de Comunicações e Artes da USP. De segunda a sexta, das $22 \mathrm{~h}$ às $23 \mathrm{~h}$.

Segunda - Música sem Fronteiras: A música sinfônica de todo o mundo interpretada por nossas orquestras. Produção e apresentação do Prof. Dr. Mário Ficarelli.

Terça - Idéia-Criação-Interpretação: A criação musical e sua trajetória. Produção e apresentação do Prof. Dr. José Eduardo Martins.

Quarta - Violão em Tempo de Concerto: Dedicado a cinco séculos de música para violão e instrumentos de cordas. Produção e apresentação do Prof. Edélton Gloeden.

Quinta - Bastidores: espaço aberto para a música de todos os tempos e gêneros. Dedicado aos mestres do trompete e dos metais. Produção e apresentação do Prof. Sérgio Cascapera.

Sexta - Tendências: dedicado às novas tendências da música instrumental. Produção e apresentação da Prof $^{a}$ Maria José Carrasqueira.

ALQUIMIA - Programa enfocando a música New Age. Produção e apresentação 
de Áureo Corrá. Segundas, quartas e sextasfeiras das $23 \mathrm{~h}$ às $24 \mathrm{~h}$.

MUNDO NEGRO - BRASILAMEFRICARIBE - Enfoca a música e a cultura negra e os principais debates travados pela comunidade. Produção e apresentação de Dulce Maria Pereira. Terças, das $23 \mathrm{~h}$ às $24 \mathrm{~h}$.

\section{EXPRESSO DA MEIA-NOITE -} Programa diário voltado à experimentação musical e ao lançamento de novos músicos, intérpretes e compositores. Produção e apresentação de Sálvio Santana. Diariamente, das $24 \mathrm{~h}$ às $2 \mathrm{~h}$.

PLANETA SOM - Enfoca a música étnica com informações sobre as comunidades a que pertencem e gravações raras. Produção e apresentação: Juliano Spyer e Maurício Monteiro. Sábado, das $7 \mathrm{~h}$ às $8 \mathrm{~h}$, com reprises aos domingos, das $15 \mathrm{~h}$ às $16 \mathrm{~h}$.

Resumo: A Rádio USP comemorou 18 anos de existência e mantém hoje uma programação eclética, misturando informaçōes, música, prestação de serviços e projetos educativos. Tem buscado desempenhar o papel de aproximaçăo da Universidade com a sociedade, divulgando sua produção e, ao mesmo tempo, tornar-se um diferencial no quadro de emissoras de São Paulo.

Palavras-chave: Rádio USP, rádio educativa, música, serviços, projetos educativos, informação.
MEMÓRIA - Gravações raras com a história do país contada pelo rádio. Produção e apresentação: Mílton Parron. Sábados, das $11 \mathrm{~h}$ às $12 \mathrm{~h}$.

UMA JANELA PARA O MUNDO Debates com convidados do meio acadêmico e intelectual. Programa produzido pelo Instituto de Estudos Avançados da USP. Sábados, das $15 \mathrm{~h}$ às $15 \mathrm{~h} 30$.

CLIP INFORMÁTICA - Programa jornalístico com as novidades do mundo da informática. O programa inclui ainda debates sobre o tema e a transmissão de softwares pelo rádio. Produção e apresentação de Alexandre Fejes Neto. Domingos, das $11 \mathrm{~h}$ às $12 \mathrm{~h}$.

O SAMBa PEde PASSAGeM Programa tradicional da Rádio USP (com mais de 16 anos de existência), enfocando o mundo do samba em São Paulo e os novos lançamentos do gênero. Sábados e domingos, das $20 \mathrm{~h}$ às $24 \mathrm{~h}$.

Abstract: Radio USP celebrated its 18 year anniversary and keeps today an ecletic programming, mixing news, information, music and educational projects. It has been searching an approach between the University and society, showing its production and, at the same time, becoming different form the others in Sao Paulo.

Key-words: Radio USP, educational radio, music, information, educational projects, services. 